\title{
Desordens Mitocondriais
}

\author{
Célia Harumi Tengan ", Acary Souza Bulle Oliveira ** \\ Beatriz Hitomi Kiyomoto, Alberto Alain Gabbai
}

\section{RESUMO}

As desordens mitocondriais são um grupo heterogêneo de doenças com manifestaçōes clinicas que variam desde miopatia pura até sindromes com comprometimento encefálico e sistêmico. São caracterizadas morfologicamente pelo aparecimento de acúmulo mitocondirial anômalo (raggeo red fibers) e sua base bioquimica é uma disfunção no processo de fosforilação oxidativa que ocorre na mitocôndria. Recentemente, foram descobertas mutaçöes no DNA mitocondrial (DNAmit) associadas a diversos tipos de mitocondriopatias. Estas alteraçōes podem ser classificadas em mutaçōes de ponto, deleçōes, duplicações e depleção. Além das mutaçōes no DNAmit, existem alteraçōes no DNA nuclear que exercem influências sobre a funçāo do DNAmit.

\section{UNTERMOS}

Citopatia mitocondrial. Mitocondria. DNA mitocondria

Mestre en Neurologia da Escola Paulista de Medicina.

* Doutor em Neurologia da Escola Paulista de Medicina.

** Prof. Adjunto, Doutor, Chefe do Setor de Neuromuscular da Disciplina de Neurologia da Escola Paulista de Medicina.

\section{INTRODUÇÃO}

As desordens mitocondriais são um grupo de doenças, bastante heterogêneo do ponto de vista clínico e bioquímico, mas que apresentam em comum um substrato anátomo-patológico que consiste numa proliferação mitocondrial anômala $^{8,18}$. A presença de "ragged red fibers" (RRF) é o maior selo diagnóstico destas doenças.

O primeiro caso de miopatia mitocondrial foi descrito parcialmente por Emster et al ${ }^{11}$ e redescrito com mais detalhes em 1962, por Luft et al ${ }^{15}$. No início dos anos 70 outros casos começaram a ser relatados ${ }^{2,14}$ incluindo mais tarde análise bioquímica realizada por DiMauro et $\mathrm{al}^{6}$. Desde então, outros casos com os mais variados fenótipos têm sido relatados, baseando-se sempre na presença de alterações morfológicas mitocondriais ${ }^{10}$.

Vários termos já foram utilizados para denominar as desordens mitocondriais: oftalmoplegia plus ${ }^{9}$, doença oculo-crânio-somática com $\operatorname{RRF}^{20}$, encefalopatia mitocondrial $^{24}$, citopatia mitocondrial $^{10}$.

Baseados nas alterações morfológicas, várias síndromes clínicas foram descritas, não só com envolvimento muscular puro mas também do sistema nervoso central. Podemos destacar alguns exemplos destas síndromes:

OEPC (oftalmoplegia externa progressiva crônica)

MELAS (mitochondrial encephalopathy, lactic acidosis e stroke)

MERRF (myoclonic epilepsy e ragged red fibers)

Kearns-Sayre Syndrome (KSS) (oftalmoplegia, degeneração pigmentar da retina, distúrbio de condução cardíaca e hiperproteinorraquia)

Queen Square Disease (atraso do desenvolvimento motor, doença ocular degenerativa, demência, epilepsia, fraqueza e neuropatia)

Leber's hereditary optics atrophy (LHON) (cegueira ao redor dos 20 anos de idade) 


\section{MITOCÔNDRIA}

A mitocôndria é a organela essencial para a produção de ATP através do processo de respiração celular e fosforilação oxidativa. Apesar desta grande importância, o estudo desta organela evoluiu de forma lenta. Ela foi reconhecida como fonte de energia celular em 1898, mas, somente em 1972, pesquisadores observaram pela primeira vez, anormalidades mitocondriais através de biópsia muscular (RRF) ${ }^{20}$. No mesmo ano, pesquisadores também descobriram que as mitocôndrias têm o seu próprio DNA para codificar proteínas (DNAmit). A despeito deste início tardio, ao redor de 1981, o DNAmit foi sequenciado no genoma humano ${ }^{1}$. O DNAmit da levedura Saccharomyces cereviseae tem cerca de 70 mil pares de base (pb) que não codificam proteínas, RNA ribossômico ou RNA transportador. Ao longo da evolução, essas seqüências foram sendo eliminadas do DNAmit, de tal modo que os organismo superiores apresentam uma molécula menor e muito econômica, é uma molécula de DNA que não contém introns. Hoje, sabe-se que o DNAmit é uma molécula circular, composta de $16567 \mathrm{pb}$, contendo 37 genes que codificam 13 proteínas, 22 RNAs transportadores e 2 RNAs ribossômicos. Todos esses genes codificam ou estão associados com a síntese de subunidades de enzimas para o sistema de fosforilação oxidativa. Embora os peptídeos codificados pelo DNAmit tenham fundamental importância, eles representam somente uma pequena proporção da proteína total mitocondrial. A maioria das proteínas mitocondriais são codificadas pelo DNA nuclear, sintetizado no citoplasma e transportado para a mitocôndria ${ }^{7}$. Evidências mostram que o genoma nuclear controla o genoma mitocondrial em um sistema complexo. As proteínas codificadas pelo DNAmit são sintetizadas dentro da mitocôndria e só ficam ativas depois que se associam a proteínas sintetizadas no citoplasma (codifjcadas pelo DNAnuclear) e importadas para dentro da mitocôndria.

Para a produção do ATP, a maior molécula carregadora de energia, as células aeróbicas oxidam carbohidratos, lípides e proteínas para gerar e estocar energia, produzindo trabalho e calor. Enzimas essenciais para este processo (conhecidas coletivamente como respiração celular e fosforilação oxidativa) são encontradas na mitocôndria. Se a respiração celular é quebrada em qualquer ponto, a célula pode não funcionar normalmente. Células que requerem mais energia, tais como as do cérebro, músculo, olhos $\mathrm{e}$ coraçạ̃o, têm o maior número de mitocôndrias e são os principais sítios de desordens mitocondriais .

\section{CLASSIFICAÇÃO}

Inicialmente as desordens mitocondriais foram classificadas, de acordo com as suas características clínicas, em síndromes (OEPC, MERRF, MELAS, LHON, KSS), mas muitas variantes eram observadas, dificultando o diagnóstico diferencial entre elas. Foi então proposta uma classificação bioquímica, baseada nos defeitos enzimáticos na função mitocondrial.

Sabe-se que a cadeia respiratória compõe-se de 5 complexos enzimáticos e 2 carregadores móveis de elétrons. Os complexos I, II, III e IV participam do transporte de elétrons através de reações de óxido-redução; o complexo V é responsável pela síntese de ATP. Estes complexos permanecem ancorados na membrana interna das mitocôndrias. Existem 2 carregadores móveis, co-enzima q e citocromo-c, que se encarregam do tráfego de elétrons entre eles. Os doadores de elétrons na cadeia respiratória são moléculas pequenas, NADH e succinato, que se formam na matriz mitocondrial no ciclo de Krebs (Fig 1). A tabela 1 mostra a classificação bioquímica das doenças mitocondriais.

\section{Tabela 1. Classificação bioquímịca das desordens mitocondriais.}

1. Defeitos do transporte:
a. Deficiência de CPT
b. Deficiência de carnitina
c. Defeito na captação da FAD

2. Defeitos na utilização do substrato
a. Deficiência da piruvato carboxilase
b. Deficiência do complexo piruvato desidro- genase
c. Defeitos da beta-oxidação

3. Defeitos do ciclo de Krebs
a. Deficiência da fumarase
b. Deficiência da alfa-cetoglutarato dehidro- genase

4. Defeitos do acoplamento da fosforilação oxidativa

5. Defeitos da cadeia respiratória
a. Deficiência do complexo 1
b. Deficiência do complexo II
c. Deficiência do complexo III
d. Deficiência do complexo IV
e. Deficiência do complexo $\mathrm{V}$
f. Defeitos combinados dos componentes da cadeia respiratória

A utilidade do uso exclusivo de critérios clínicos para a identificação e classificação das doenças mitocondriais é limitada, porque não há um quadro clínico único. A classificação bioquímica, também é insuficiente, pois um mesmo erro enzimático pode apresentar-se sob diferentes formas clínicas. Por exemplo, na deficiência do complexo I o 
quadro clínico inclui: intolerância ao exercício, fraqueza muscular progressiva, demência, epilepsia, distonia, atrofia óptica, oftalmoplegia. A deficiência do complexo III pode manifestar-se por intolerância ao exercício, fraqueza muscular progressiva, cãibras, ptose palpebral, ataxia, surdez, mioclonia. Já a deficiência de Citocromo C Oxidase (COX), o último componente da cadeia respiratória (complexo IV), causa diversos fenótipos: (a)hipotonia, cardiopatia, encefalopatia, disfunção renal, intolerância ao exercício; (b) miopatia infantil benigna ou maligna; (c) MERRF; (d) KSS; (e) Síndrome de Leigh (retardo no desenvolvimento motor, ataxia, atrofia óptica, oftalmoplegia, ptose, nistagmo, distonia, tremor, sinais piramidais, anormalidades respiratórias); (f) Doença de Menkes (tricopoliodistrofia, desordem do cobre, epilepsia, retardo desenvolvimento motor, anormalidades no cabelo, nos ossos e no fígado).

As doenças decorrentes de alterações do DNAmit também foram classificadas por Rowland et al ${ }^{22}$ em 2 categorias: síndromes com deleções (KSS e oftalmoplegia extema progressiva) e síndromes com mutações de ponto (LHON, MELAS, MERRF).

DeVivo $^{5}$ (1993) propõe uma classificação mais abrangente, bașeada em critérios bioquímicos e genéticos, e que também considera as desordens mitocondriais adquiridas, como infecciosas, tóxicas, drogas e envelhecimento (Tabela 2).

\section{Tabela 2. Classificação bioquímica e genética das doenças mitocondriais.}

A. Formas hereditárias

1. Defeitos do DNA nuclear
a. defeitos do transporte de substrato
b. defeitos na utilização do substrato
c. defeitos do ciclo de Krebs
d. defeitos do acoplamento da fosforilação oxidativa
e. defeitos da cadeia respiratória
f. defeitos da importação da proteína
g. defeitos na sinalização intergenômica

2.Defeitos do DNA mitocondrial

a. grandes rearranjos esporádicos

b. grandes rearranjos transmitidos

c. mutações de ponto afetando genes estruturais

d. mutaçōes de ponto afetando genes de síntese

B. Formas adquiridas
1. infecciosa (p.ex. Síndrome de Reye)
2. tóxica (MPTP)
3. drogas (AZT)
4. envelhecimento

\section{MITOCÔNDRIAS}

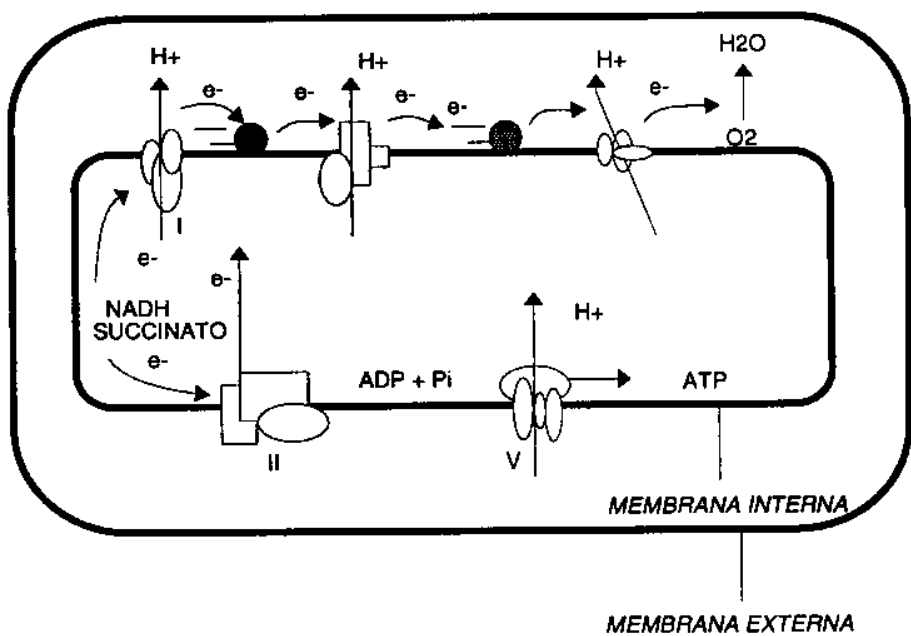

FIGURA 1.

CADEIA RESPIRATÓRIA

(reprinted com permissão - modificado. Moraes CT, DiMauro S, Schmidt B, Schon EA. - Doenças mitocondriais. Ciência Hoje, 1990, 12: 46-52.)

Cadeia composta de cinco complexos enzimáticos $\theta$ dois carregadores móveis de elétrons. Os complexos II II HI $\in$ IV participam do transporte de elétrons, através das reaçöes de oxidorreduçāo. O complexo $V$ é responsável pela sintese de ATP. A coenzima $Q$ e o citocromo $C$ se encarregam do tráfego de elétrons entre eles. Os doadores iniciais de elétrons na cadeia respiratónia são o NADH e o succinato que se formaim na matriz mitocondrial no cicio de Krebs.

\section{ASPECTOS GENÉTICOS}

O corpo humano tem aproximadamente um trilhão de células e um quadrilhão de mitocôndrias, que se multiplicam em poucas semanas; nem todas estas replicações são perfeitas. Então, durante a vida, há enormes chances para que ocorram mutações no DNAmit. Algumas vezes, uma mutação deletéria torna-se fixa e passa para gerações celulares subseqüentes.

Diversos erros genéticos podem acontecer: 1 . mutações nos genes nucleares codificadores de proteínas mitocondriais; 2. mutações nos genes mitocondriais; 3 . mutações envolvendo o processo de importação das proteínas mitocondriais; 4. mutações envolvendo o controle do genoma nuclear sobre o genoma mitocondrial; 5. mutações afetando grupos prostéticos de enzimas mitocondriais (por exemplo: síndrome de Menkes).

\section{Doenças associadas com deleções do DNAmit}

A OEPC, clinicamente caracterizada por oftalmoplegia e ocasionalmente, fraqueza muscular progressiva de início na infância, foi associada a grandes deleções do DNAmit, em 70 a $80 \%$ dos pacientes. Pelo fato de não haver diferenças na incidência e tipo de deleções do DNAmit em pacientes com KSS típica e pacientes que apresentam 
somente oftalmoplegia externa progressiva, a KSS pode ser incluída na categoria de OEPC. Aproximadamente $80 \%$ dos pacientes com KSS e $50 \%$ dos pacientes só com miopatia ocular tem deleções do seu DNAmit ${ }^{16}$. A gravidade da apresentação clínica não está correlacionada com o tamanho e localização da deleção, ou com proporção do DNAmit mutante no músculo. Entretanto, pacientes com apresentação clínica mais severa apresentam maior porcentagem de DNAmit mutante em tecidos não musculares.

Deleções múltiplas do DNAmit também foram descritas em algumas famílias, com transmissão autossômica dominante ${ }^{26}$. As deleções múltiplas foram associadas a diversos sintomas: oftalmoplegia externa progressiva, neuropatia, deficiência mental, retardo psicomotor e alterações gastrointestinais ${ }^{4,27}$.

\section{Doenças associadas com mutações de ponto do DNAmit}

Ao contrário das deleções mitocondriais, que são usualmente esporádicas, as mutações de ponto do DNAmit são geralmente associadas a transmissão por herança materna. Oitenta porcento dos pacientes com MELAS têm uma mutação de ponto no nucleotídeo 3243 e $10 \%$ no nucleotídeo 3271. Os pacientes com mutações 3243 e 3271 não apresentam diferenças clínicas ou anatomo-patológicas entre eles $^{12,13}$.

Na MERRF foi detectada uma mutação A-para-G no nucleotídeo 8344 , tanto em pacientes, como em familiares assintomáticos. O DNAmit mutante e normal foram detectados em um estado de heteroplasmia em vários tecidos, com diferentes proporções. No músculo de pacientes sintomáticos geralmente mais de $80 \%$ do DNAmit era mutante. No entanto, proporções altas de DNAmit mutante também foram encontradas em familiares assintomáticos, tornando difícil a correlação com o grau de severidade clínica ${ }^{3,23}$.

Quatro mutações diferentes foram encontradas em pacientes com LHON, a mais freqüente é a substituição G-para-A no nucleotídeo 11778 no DNAmit, que converte uma arginina para uma histidina para a subunidade 4 da NADH desidrogenase. A segunda mutação mais frequiente é a que ocorre no nucleotídeo 3460 (mutação G-para-A). Não se sabe o defeito bioquímico decorrente desta mutação ${ }^{19}$.

\section{Depleção do DNAmit}

Moraes et al ${ }^{17}$ descreveram 4 pacientes que não apresentavam mutações no DNAmit mas apresentavam quantidade muito reduzida do DNAmit, cerca de $98 \%$. Tratava-se de uma encefalomiopatia mitocondrial infantil, com deficiência de COX e com evolução fatal. A partir daí, outros casos foram descritos e observou-se que havia uma correlação entre grau de depleção e gravidade dos sintomas clínicos ${ }^{25}$.

\section{Duplicação do DNAmit}

Rotig et al ${ }^{21}$ descreveram 2 pacientes com quadro de tubulopatia renal proximal no primeiro ano de vida, acompanhado de diabetes mellitus, alterações na pele, fraqueza muscular e ataxia cerebelar. Observou-se uma duplicação do DNAmit de 26kb.

Apesar dos grandes avanços nos estudos com DNAmit, os aspectos fisiopatológicos das desordens mitocondriais não estão totalmente elucidados. Uma mesma mutação no DNAmit pode levar a vários fenótipos e estar presente mesmo em indivíduos assintomáticos. A grande heterogeneidade desta entidade pode ser explicada pelo fenômeno de heteroplasmia, ou seja, em um tecido pode-se encontrar DNAmit normal e mutante, em variáveis proporções. O que determina o fenótipo e o grau de manifestação é a proporção de DNAmit mutante presente no tecido, é necessário que se atinja um nível limiar de DNAmit mutante para que a doença se manifeste. Por exemplo, na OECP é necessário que se atinja um limiar de $70 \%$ de DNAmit mutante, no MELAS, $95 \%$ e no MERRF, $90 \%^{19}$. Alterações do DNAmii não são os únicos responsáveis pelas desordens mitocondriais. $\mathrm{O}$ DNA nuclear também exerce influências sobre o DNAmit, e um erro neste processo pode levar a alguns tipos de mitocondriopatias, explicando o achado de herança tipo autossômica dominante em alguns casos. A análise das famílias dos pacientes é bastante difícil, não só pela sua heterogeneidade clínica, mas também porque o grau de comprometimento do DNAmit é bastante variável de pessoa para pessoa, de tecido para tecido e de célula para célula. Existem pacientes assintomáticos com grande proporção de DNAmit mutante, e aqueles sintomáticos com pequena proporção. Ainda não se conseguiu definir uma correlação clara entre a mutação do DNAmit, com o defeito bioquímico decorrente desta alteração, por isso é bem provável que outros fatores também estejam envolvidos no desenvolvimento da doença.

\section{SUMMARY}

Mitochondrial disorders are a very heterogeneous group, with clinical manifestations varying from a pure myopathy to systemic syndromes with encephalopathy. Anomalous mitochondrial proliferation (ragged red fibers) is the most typical morphological feature and there is a biochemical defect in oxidative fosiorilation in mitochondria. Recently, mitochondrial DNA (mitDNA) mutations were associated to several mitochondrial disorders. These abnormalities are classified in point mutations, deletions, duplications and depletion. Besides mitDNA mutations, nuclear DNA abnormalities may also occur.

KEY WORDS:

mitochondrial cytopathy, mitochondria, mitochondrial DNA 


\section{Bibliografia}

1. ANDERSON, S.A.; BANKIER, A.T.; BARREL, B.G.; BRUIJN, M.H.L.; COULSON, A.R.; DROUIN, J.; EPERON, I.C.; NIERLICH, D.P.; ROE, B.A.; SANGER, F.; SCHREIER, P.H.; SMITH, A.J.H.; STADEN, R. \& YOUNG, I.G. - Sequence and organization of the human mitochondrial genome. Nature, 290: 457-465, 1981.

2. AFIFI, A.K.; IBRAHIM, M.Z.M.; BERGAMN, R.A.; HAYDAR, N.A.; MIRE, J.; BAHUTH, N. \& KAYLANY, F. - Morfologic features of hypermetabolic mitochondrial disease. A light microscopic, histochemical and electron microscopic study. J. Neurol. Sci. 15: 271-290, 1972.

3. BERKOVIC, S.F.; SHOUBRIDGE, E.A.; ANDERMANN, F.; ANDERMANN, E.; CARPENTER, S. \& KARPATI, G. - Clinical spectrum of mitochondrial DNA mutation at base pair 8344. Lancet, 338: 457, 1991.

4. CORMIER, V.; ROTIG, A.; TARDIEU, M.; COLONNA, M.; SAUDUBRAY, J-M. \& MUNNICH, A. - Autosomal dominant deletions of the mitochondrial genome in a case of progressive encephalomyopathy. AM. J. HUM. GENET., 48: 643-648, 1991.

5. DEVIVO, D.C. - Diagnostic aproach to a mitochondrial encephalomyopathy: clinical and laboratory features.In: American Academy of Neurology Congress 45, New York, April 25 - May1, 1993. Annual Meeting. Minneapolis, pp 331-1 - 331-40 American Academy of Neurology, vol 2, 1993.

6. DIMAURO, S.; BONILLA, E.; LEE, C.P.; SCHOTLAND, D.L.; SCARPA, A.; CONN, H, JR. \& CHANCE, B. - Luft's disease. Further biochemical studies of skeletal muscle in the second case. J. Neurol. Sci. , 27: 217-232, 1976.

7. DIMAURO, S.; BONILLA, E.; LOMBES, A.; SHANSKE, S.; MINETTI, C. \& MORAES, C.T. - Mitochondrial encephalomyopathies. Neurologic Clinics, 8(3):483-506, 1990.

8. DIMAURO, S.;BONILLA, E.;ZEVIANI, M.; NAKAGAWA, M. \& DeVIVO, D. - Mitochondrial myopathies. Ann Neurol, 17: 521-538, 1985.

9. DRACHMAN, D.A. - Ophthalmoplegia plus. The neurodegenerative disorders associated with progressive external ophthalmoplegia. Arch. Neurol., 18: 654-674, 1968.

10.EGGER, J.; LAKE, B.D. \& WILSON, J. - Mitochondrial cytopathy. A multisystem disorder with ragged-red fiber on muscle biopsy. Arch. Dis. Child., 56: 741-752, 1981.

11.ERNSTER, L.; IKKOS, D. \& LUFT, R. - Enzymatic activities of skeletal muscle mitochondria: a tool in clinical metabolic research. Nature, 184 1851-1854, 1959.

12.GOTO, Y.; NONAKA, I. \& HORAI, S. - A mutation in the tRNALeU(UUR) gene associated with the MELAS subgroup of mitochondrial encephalomyopathies. Nature, 348: 65t-653, 1990.

13.GOTO, Y.; NONAKA, I. \& HORAI, S. - A new mtDNA mutation associated with mitochondrial myopathy, encephalopathy, lactic acidosis and stroke-like episodes. Blochem. Biophys Acta, 1097: 238-240, 1991.

14.HAYDAR, N.A.; CONN, H.L. JR.; AFIFI, A.; WAKID, N.; BALLAS, S. \& FAWAS, K. - Severe hypermetabolism with primary abnormality of skeletal muscle mitochondria. Functional and therapeutic effects of chloramphenicol treatment. Ann. Intern. Med., 74: 548-558, 1971.

15.LUFT, R.; IKKOS, D.; PALMIERI, G.; ERNSTER, L. \& AFZELIUS, B. A case of severe hypermetabolism of non thyroid origin with a defect in the maintenance of mitochondrial respiratory control: a correlated clinical, biochemical and morphological study. J. Clin. Invest., 41: 1776-1804, 1962.

16.MORAES, C.T.; DiMAURO, S.; ZEVIANI, M.; LOMBES, A.; SHANSKE, S.; MIRANDA, A.F.; NAKASE, H.; BONILLA, E. ET AL. - Mitochondrial DNA deletions in Progressive External Ophthalmoplegia and KearnsSayre syndrome. N. Engl. J. Med., 320: 1293-1299, 1989.

17.MORAES, C.T.; SHANSKE, S.; TRITSCHLER, H.J.; APRILLE, J.R.; ANDREETTA, F.; BONILLA, E.; SCHON, E.A. \& DIMAURO, S. Mitochondrial DNA depletion with variable tissue specificity: a novel genetic abnormality in mitochondrial diseases. Am. J. Hum. Genet., 48: 498-501, 1991.

18.MORGAN-HUGHES, J.A. - Mitochondrial myopathies. In: Mastaglia,FL \& Walton,J, eds. Skeletal muscle pathology, Edinburgh Churchill - Livingstone, 1982 pp 309-339.

19.NONAKA, I. - Mitochondrial diseases. Current Opinion in Neurology and Neurosurgery, 5: 622-632, 1992.

20.OLSON, W.; ENGEL, WK.; WALSH, G.O. \& EINAUGLER, R. - Oculocraniosomatic neuromuscular disease with "ragged-red"fibers. Histochemical and ultrastructural changes in limb muscle of a group of patients with idiopatic progressive external ophthalmoplegia. Arch. Neurol, 26: 193-211, 1972.

21.ROTIG, A.; BESSIS, J.L.; ROMERO, N.; CORMIER, VM.; SAUDUBRAY, J-M.; NARCY, P.; LENOIR, G.; RUSTIN, P. \& MUN$\mathrm{NICH}, \mathrm{A}$. Mattemally inherited duplication of the mitochondrial genome in a syndrome of proximal tubulopathy, diabetes mellitus, and cerebellar ataxia. Am J. Hum. Genet., 50: 364-370, 1992.

22.ROWLAND, L.P.; BLAKE, D.M.; HIRANO, M. ET AL - Clinical syndromes associated with ragged red fibers. Rev. Neurol (Paris), 147: 467 - 473, 1991

23.SEIBEL, P.; DEGOUL, F.; BONNE, G.; ROMERO, N.; FRANÇOIS, D.; PATURNEAU-JOUAS, M.;ZEIGLER, F.; EYMARD, B.; FARDEAU, M.; MARSAC, C. \& KADENBACH, B. - Genetic biochemical and pathophysiological characterization of a familial mitochondrial encephalomyopathy (MERRF). J. Neurol. Sci., 105: 217-224, 1991.

24.SHAPIRA, Y.; HAREL, S. \& RUSSEL, A. - Mitochondrial encephalomyopathies. A group of neuromuscular disorders with defects in oxidative metabolism. Isr. J. Med. Sci., 13: 161 - 164, 1977.

25.TRITSCHLER, H-J.; ANDREETTA, F.; MORAES, C.T.; BONILLA, E.; ARNAUDO, E.; DANON, M.J.; GLASS, S.; ZELAYA, B.M.; VAMOS, E.; TELERMAN-TOPPET, N.; SHANSKE, S.; KADENBACH, B.; DiMAURO, S. \& SCHON, E.A. - Mitochondrial myopathy of childhood associated with depletion of mitochondrial DNA. Neurology, 42: 209217, 1992.

26.ZEVIANI, M.; SERVIDEI, S.; GELLERA, C.; BERTINI, E.; DiMAURO, S. \& DiDONATO, S. - An autosomal dominant disorder with multiple deletions of mitochondrial DNA starting at the D-loop region. Nature, 339: 309-311, 1989.

27.ZEVIANI, M.; BRESSOLIN, N.; GELLERA, C.; BORDONI, A.; PANNACCI, M.; AMATI, P.; MOGGIO, M. ET AL. - Nucleus-driven multiple large-scale deletions of the human mitochondrial genome: a new autosomal dominant disease. Am J. Hum. Genet., 47: 904-914, 1990. 